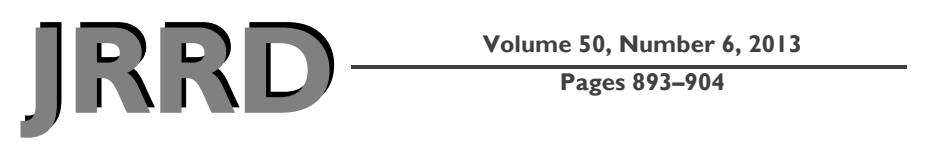

\title{
Blast-related ear injuries among U.S. military personnel
}

\author{
Amber L. Dougherty, MPH; ${ }^{1 *}$ Andrew J. MacGregor, PhD, MPH; ${ }^{1}$ Peggy P. Han, MPH; ${ }^{1}$ Erik Viirre, MD, PhD; ${ }^{2}$ \\ Kevin J. Heltemes, MPH; ${ }^{\mathbf{1}}$ Michael R. Galarneau, MS ${ }^{\mathbf{1}}$ \\ ${ }^{1}$ Department of Medical Modeling, Simulation, and Mission Support and ${ }^{2}$ Warfighter Performance Department, Naval \\ Health Research Center, San Diego, CA
}

\begin{abstract}
Blast-related ear injuries are a concern during deployment because they can compromise a servicemember's situational awareness and adversely affect operational readiness. The objectives of this study were to describe blast-related ear injuries during Operation Iraqi Freedom, identify the effect of hearing protection worn at the point of injury, and explore hearing loss and tinnitus outcomes within one year after injury. The Expeditionary Medical Encounter Database was used to identify military personnel who survived blast-related injury, and it was linked with outpatient medical databases to obtain diagnoses of hearing loss and tinnitus. The prevalence of ear injuries was $30.7 \%(1,223$ of 3,981). The most common ear injury diagnoses were "inner or middle ear injury involving tinnitus" and tympanic membrane (TM) rupture. Hearing protection reduced the odds of ear injury involving tinnitus. Personnel with TM rupture had higher odds of hearing loss (odds ratio $[\mathrm{OR}]=6.65$, 95\% confidence interval $[\mathrm{CI}]=5.04-8.78)$ and tinnitus outcomes $(\mathrm{OR}=4.34,95 \% \mathrm{CI}=3.12-6.04)$ than those without TM rupture. Ear injuries and hearing impairment are frequent consequences of blast exposure during combat deployment. Hearing protection is warranted for all servicemembers at risk of blast exposure.
\end{abstract}

Key words: auditory, blast, combat, deployment, ear injury, hearing loss, hearing protection, military, tinnitus, tympanic membrane rupture.

\section{INTRODUCTION}

The increased use of improvised explosive devices (IEDs) by terrorists and insurgent activities in Iraq and
Afghanistan has yielded an unprecedented proportion of blast-related casualties compared with previous wars [13 ], with recent estimates indicating blasts are responsible for approximately 75 percent of U.S. combat casualties in Operations Iraqi and Enduring Freedom [4]. The ear is the most vulnerable and typically the first organ to incur injury from a blast (or pressure) wave [5-7]. Although hearing protection devices are available in the combat theater, recent anecdotal reports indicate some troops decline to wear hearing protection for fear of reduced situational awareness on the battlefield [8-10]. Not surprisingly, blast injury to the ear has emerged among deployed military personnel [11-12].

Blast-related ear injuries often present as damage to the sensitive structures of the inner and middle ear, such as the cochlea, ossicular chain, tympanic membrane (TM), and vestibular system [5,13-14]. Damage to these components

Abbreviations: AIS $=$ Abbreviated Injury Scale, $\mathrm{CI}=$ confidence interval, DEERS $=$ Defense Enrollment Eligibility Reporting System, DMDC = Defense Manpower Data Center, E code $=$ external cause of injury code, EMED = Expeditionary Medical Encounter Database, ICD-9-CM = International Classification of Diseases-9th Revision-Clinical Modification, IED $=$ improvised explosive device, ISS = Injury Severity Score, $\mathrm{OR}=$ odds ratio, $\mathrm{TM}=$ tympanic membrane.

*Address all correspondence to Amber L. Dougherty, MPH; Naval Health Research Center, 140 Sylvester Rd, San Diego, CA 92106-3521; 619-368-6853; fax: 619-5538378. Email: amber.dougherty@med.navy.mil http://dx/doi.org/10.1682/JRRD.2012.02.0024 
of the auditory system may result in transient or permanent impairment, such as hearing loss and tinnitus (ringing in the ears) [15-17]. In 2010, hearing loss and tinnitus were the top two service-connected disabilities among veterans receiving compensation [18], and they are increasing at a dramatic rate [18-20]. From fiscal years 2006 to 2010, the number of veterans who received new compensation awards for "impairment of auditory acuity" grew by more than 72 percent [18]. The total annual expense to deliver hearing healthcare services and compensate veterans for hearing impairment has been estimated to exceed \$1 billion [20].

Blast-related ear injuries are a primary concern during deployment because they can compromise an individual's hearing acuity and, as a result, may reduce situational awareness and adversely affect operational readiness [21]. In a communication-dependent environment, such as the battlefield, where listening can be critical for combat effectiveness and survival, a hearing-impaired servicemember may become "more of a liability than an asset" [22]. As such, the prevention, identification, and treatment of blast-related ear injuries are critical to the overall mission and health of the force. The objectives of this study were to (1) assess the prevalence and types of blastrelated ear injuries among servicemembers wounded in Operation Iraqi Freedom; (2) examine the effect of hearing protection worn during the blast injury event; and (3) identify the association between specific ear injuries, new-onset hearing loss, and tinnitus outcomes within $1 \mathrm{yr}$ after injury.

\section{METHODS}

\section{Study Population}

The study population was obtained from the Expeditionary Medical Encounter Database (EMED), which is maintained by the Naval Health Research Center in San Diego, California. The EMED contains information abstracted from medical records of U.S. military personnel completed by providers at forward-deployed Navy-Marine Corps treatment facilities in the combat zone (i.e., nearest to the point of injury) and throughout the continuum of care [23]. Records from each level of care are reviewed by certified nurse coders at the Naval Health Research Center and assigned codes from the International Classification of Diseases-9th Revision-Clinical Modification (ICD-9-CM), Abbreviated Injury Scale (AIS) 2005, and Injury Severity Score (ISS) coding systems [24-26].
At the time of this analysis, there were 13,226 military personnel in the EMED with an injury event that occurred during Operation Iraqi Freedom. Of these, 4,817 were injured in a blast during the study period between March 1, 2004, and August 31, 2008 (Figure). A blast injury event was defined as the presence of a blast-related mechanism of injury and/or ICD-9-CM external cause of injury code (E code) in the EMED clinical record. The blast mechanisms of injury included aerial bomb, grenade, IED, vehicle-borne IED, landmine, mortar, rocket-propelled grenade, rocket, and unexploded ordinance. The blast E codes were those indicating injury from war operations by antipersonnel bomb (fragments) (E991.3), other and unspecified fragments (E991.9), and other explosion (E993).

Personnel were then matched to identifying information in the Defense Enrollment Eligibility Reporting System (DEERS) and deployment information in the Defense Manpower Data Center (DMDC); personnel who did not match to the DEERS $(n=87)$ or whose injury date did not match to deployment dates in the DMDC $(n=148)$ databases were excluded. Military personnel were also excluded if they did not have a clinical record from a forward-deployed NavyMarine Corps treatment facility $(n=20)$, died during the study period ( $n=141)$, or had incomplete or missing coding information $(n=440)$. The final study population consisted of 3,981 military personnel.

\section{Measures}

Blast-related ear injury was identified by AIS codes in the EMED. The AIS is an anatomical scoring system that describes an individual injury, categorizes the injury into a body region, and assigns a severity score (see Gennarelli and Wodzon for further description of the AIS [25]). The AIS codes of interest in the present analysis were ear injury, not further specified (240299.1); ear canal injury (240204.1); inner or middle ear injury, not further specified (240208.1), bilateral (240207.1), involving dizziness (240206.1), or involving tinnitus (240205.1); ossicular chain (ear bone) dislocation (240212.1), bilateral (240213.2); TM (eardrum) rupture (240216.1); and vestibular apparatus injury (240220.1). Personnel without one of these AIS codes were categorized as non-ear injury.

Military personnel in the final study population were linked to the Military Health System Data Repository to obtain hearing loss and tinnitus outcomes, in the form of ICD-9-CM diagnostic codes, from outpatient records in the Standard Ambulatory Data Records and TRICARE 


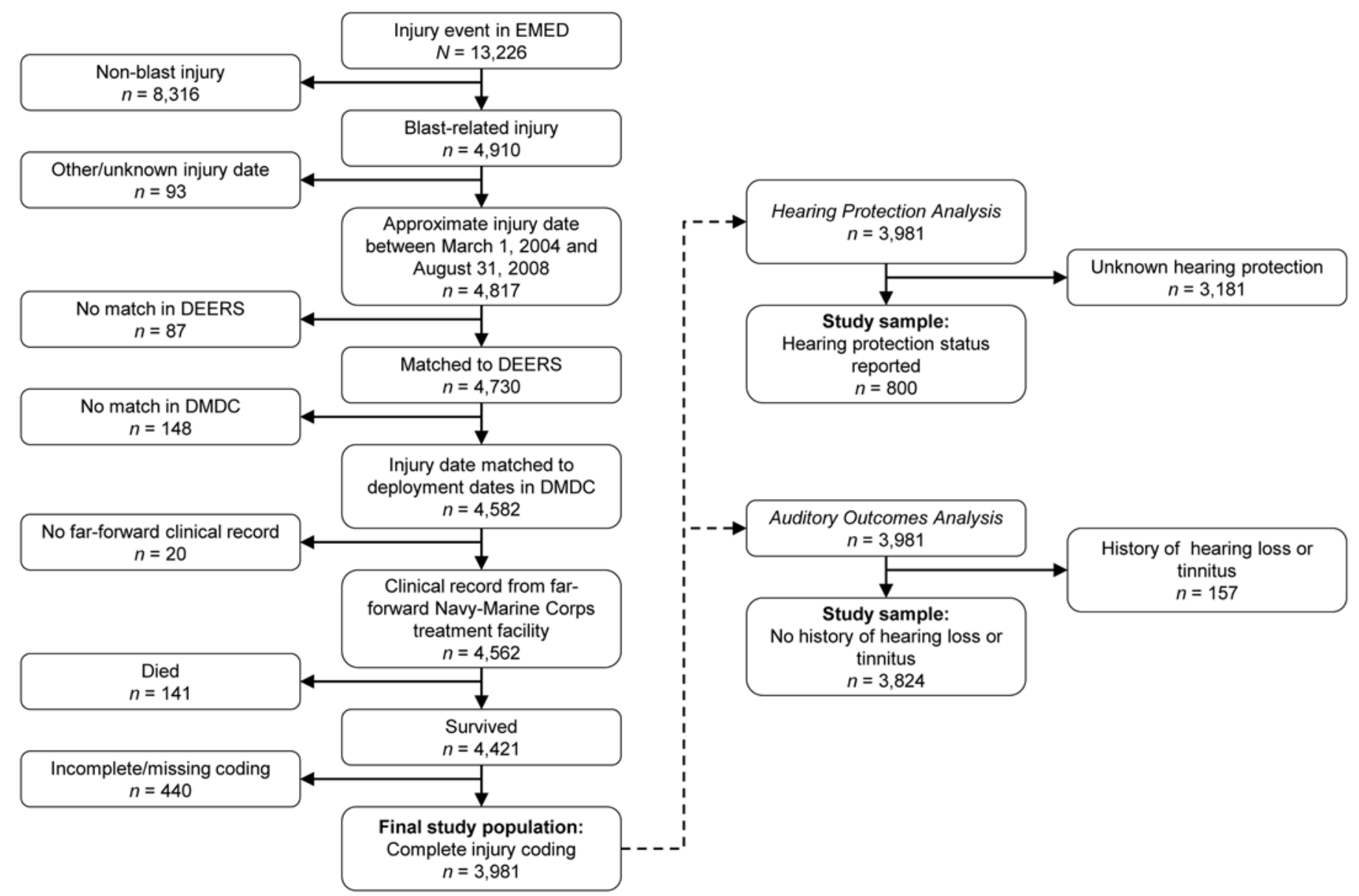

Figure.

Selection of study population and samples for hearing protection and outcomes analyses. DEERS = Defense Enrollment Eligibility Reporting System, DMDC = Defense Manpower Data Center, EMED = Expeditionary Medical Encounter Database.

Encounter Data-Non-Institutional databases. These databases were queried for ICD-9-CM codes for hearing loss (389.0-.9) and tinnitus (388.3-.32) diagnosed before injury and within $365 \mathrm{~d}$ after injury.

Demographic and military-specific variables of interest were obtained from the EMED and included age, branch of service (Army, Marine Corps, Navy, or Air Force), military rank (enlisted or officer/warrant officer), occupational specialty (infantry or other/unspecified) at the time of injury, and sex. Injury-specific variables included blast mechanism (IED, mortar, rocket-propelled grenade, grenade, landmine, or other/unspecified), hearing protection status at the time of injury (worn, not worn, or unknown), head injury, and ISS. ISS is an anatomical scoring system used to represent the overall injury severity of an individual and, for the present analy- sis, was categorized as 1 to 8 (mild/moderate injury) or 9 or higher (serious/severe) (see Baker et al. for further description of the ISS [26]).

\section{Statistical Analysis}

Differences in demographic, military, and injuryspecific characteristics by ear injury status were assessed with the independent samples $t$-test for continuous data (i.e., age) and with chi-square tests for categorical data. The overall prevalence and types of blast-related ear injuries were calculated for the study population. As shown in the Figure, two separate samples were obtained from the final study population to conduct independent analyses of (1) the effect of hearing protection worn during the blast-injury event and (2) the effect of specific ear injuries on hearing loss and tinnitus outcomes. 


\section{Hearing Protection and Ear Injury}

Only 800 personnel in the study population had hearing protection status reported in the EMED and were included in the hearing protection analysis; those with unknown hearing protection status $(n=3,181)$ were excluded. Descriptive statistics were computed for sample characteristics by hearing protection status. Univariate and multiple logistic regression were used to assess the association between hearing protection, sample characteristics, and the occurrence of the two most common blast-related ear injuries in the sample: (1) inner/middle ear injury involving tinnitus and (2) TM rupture.

\section{Hearing Loss and Tinnitus Outcomes}

For this analysis, individuals with hearing loss or tinnitus diagnosed prior to injury were excluded $(n=157)$, leaving a total sample size of 3,824 military personnel. Univariate and multiple logistic regression were used to examine the effect of specific ear injuries on hearing loss and tinnitus outcomes. Regression diagnostics were performed for all multivariable analyses, including examining covariates for multicollinearity and goodness-of-fit tests. Unadjusted and adjusted odds ratios (ORs) and 95 percent confidence intervals (CIs) are reported. All statistical analyses were performed using SPSS software version 17.0 (SPSS Inc; Chicago, Illinois).

\section{RESULTS}

During the study period, a total of 3,981 military personnel were injured in a blast during deployment in Operation Iraqi Freedom between March 1, 2004, and August 31, 2008. Of these, 30.7 percent $(n=1,223)$ were diagnosed with blast-related ear injury in theater. As shown in Table 1, personnel with ear injuries were younger, proportionately more likely to be serving in the Marine Corps, and more likely to have been injured by an IED, but less likely to be wearing hearing protection at the time of injury than those with non-ear injuries. Military rank and occupational specialty did not differ between the groups. Although head injury was more common among those with blast-related ear injuries, overall ISS was higher among those without ear injury.

The most common blast-related ear injuries, calculated as separate variables of the total study population, were inner/middle ear injury involving tinnitus ( $n=767,19.3 \%)$; TM rupture $(n=319,8.0 \%)$; and ear injury, not further specified ( $n=248,6.2 \%)$. All other ear injuries occurred in less than 1 percent of the sample, including ear canal injury ( $n=23)$; inner or middle ear injury, not further specified $(n=5)$, bilateral $(n=0)$, or involving dizziness $(n=12)$; ossicular chain (ear bone) dislocation $(n=1)$, bilateral $(n=$ $0)$; and vestibular apparatus injury $(n=1)$.

\section{Hearing Protection and Ear Injury}

Of the 800 personnel who had hearing-protection status recorded and were eligible for this analysis, 391 (48.9\%) were reported wearing hearing protection at the time of injury, and the remaining 409 (51.1\%) were reported without hearing protection. Compared with those wearing hearing protection, those without were younger and proportionately more likely to be in the Marine Corps, of enlisted rank, and serving in infantry occupations (Table 2). Blast-injury mechanism did not differ by hearing protection status (worn or not worn). Although head injury was more common among personnel without hearing protection, ISS was significantly higher in the group wearing hearing protection at the time of injury.

The most common blast-related ear injuries, inner/ middle ear injury involving tinnitus and TM rupture, were selected to examine the effect of hearing protection worn during the blast injury event. Table $\mathbf{3}$ shows the associations of these ear injuries with hearing protection status and other characteristics of the sample. In univariate analysis, military personnel with inner/middle ear injury involving tinnitus were significantly less likely to be wearing hearing protection at the point of injury than those with other injuries. They were also more likely to be serving in the Marines or Navy and to sustain concomitant head injury, but less likely to have more severe injuries overall. By contrast, military personnel with TM rupture were significantly more severely injured overall than those with other injuries and were more likely to be injured by a grenade. Hearing protection was not independently associated with TM rupture.

Multiple logistic regression was used to assess the combined effects of hearing protection and significant covariates on the occurrence of inner/middle ear injury involving tinnitus and TM rupture. After adjusting for age, service branch, head injury, and ISS, military personnel wearing hearing protection at the time of injury had reduced odds of inner/middle ear injury involving tinnitus $(\mathrm{OR}=0.57,95 \% \mathrm{CI}=0.39-0.82)$ compared with those without hearing protection. By contrast, hearing protection 
Table 1.

Association of ear injury status with sample characteristics, Operation Iraqi Freedom, 2004-2008.

\begin{tabular}{|c|c|c|c|c|}
\hline Characteristic & $\begin{array}{c}\text { Total } \\
(n=3,981)\end{array}$ & $\begin{array}{l}\text { Ear Injury } \\
(n=1,223)\end{array}$ & $\begin{array}{l}\text { Non-Ear Injury } \\
\quad(n=2,758)\end{array}$ & $p$-Value \\
\hline Age, yr (mean \pm SD) & $24.0 \pm 5.3$ & $23.8 \pm 5.1$ & $24.2 \pm 5.4$ & 0.02 \\
\hline Male & 3,930 (98.7) & $1,210(98.9)$ & 2,720 (98.6) & \\
\hline Female & $51(1.3)$ & $13(1.1)$ & $38(1.4)$ & \\
\hline Marine Corps & 2,929 (73.6) & 972 (79.5) & $1,957(71.0)$ & \\
\hline Army & $820(20.6)$ & $178(14.6)$ & 642 (23.3) & \\
\hline Navy & $226(5.7)$ & $71(5.8)$ & $155(5.6)$ & \\
\hline Air Force & $6(0.2)$ & $2(0.2)$ & $4(0.1)$ & \\
\hline Military Rank, $n$ (\%) & & & & 0.09 \\
\hline Infantry & $2,053(51.6)$ & 633 (51.8) & $1,420(51.5)$ & \\
\hline Other/Unknown & $1,928(48.4)$ & $590(48.2)$ & $1,338(48.5)$ & \\
\hline Hearing Protection, $n$ (\%) & & & & $<0.001$ \\
\hline Worn & $391(9.8)$ & $95(7.8)$ & $296(10.7)$ & \\
\hline Not Worn & 409 (10.3) & 167 (13.7) & $242(8.8)$ & \\
\hline Unknown ${ }^{*}$ & 3,181 (79.9) & $961(78.6)$ & $2,220(80.5)$ & \\
\hline Blast Mechanism, $n$ (\%) & & & & $<0.001$ \\
\hline IED & $2,872(72.1)$ & 1,002 (81.9) & $1,870(67.8)$ & \\
\hline Mortar & 338 (8.5) & $68(5.6)$ & $270(9.8)$ & \\
\hline No & $2,190(55.0)$ & $474(38.8)$ & $1,716(62.2)$ & \\
\hline Yes & $1,791(45.0)$ & 749 (61.2) & $1,042(37.8)$ & \\
\hline Injury Severity Score, $n$ (\%) & & & & $<0.001$ \\
\hline Mild/Moderate & 3,390 (85.2) & $1,078(88.1)$ & 2,312 (83.8) & \\
\hline Serious/Severe & 591 (14.8) & 145 (11.9) & 446 (16.2) & \\
\hline
\end{tabular}

was not statistically associated with TM rupture after adjusting for covariates $(\mathrm{OR}=0.86,95 \% \mathrm{CI}=0.46-1.62)$.

\section{Hearing Loss and Tinnitus Outcomes}

Of the 3,824 personnel eligible for outcome analysis, 11.6 percent $(n=444)$ were diagnosed with hearing loss and
6.1 percent $(n=233)$ were diagnosed with tinnitus within $1 \mathrm{yr}$ after blast-related injury. The associations between demographic and injury-specific variables, hearing loss, and tinnitus are shown in Table 4. The primary exposures of interest in this analysis were the two most common blastrelated ear injuries, inner/middle ear injury involving 
JRRD, Volume 50, Number 6, 2013

Table 2.

Association of hearing protection status with sample characteristics, Operation Iraqi Freedom, 2004-2008.

\begin{tabular}{|c|c|c|c|c|}
\hline Characteristic & Total $(n=800)$ & Worn $(n=391)$ & Not Worn $(n=409)$ & $p$-Value \\
\hline Age, yr (mean \pm SD) & $23.9 \pm 5.0$ & $24.5 \pm 5.0$ & $23.4 \pm 4.8$ & 0.001 \\
\hline Sex, $n(\%)^{*}$ & & & & - \\
\hline Female & $1(0.1)$ & $1(0.3)$ & $0(0)$ & \\
\hline Service, $n(\%)$ & & & & $<0.001$ \\
\hline Navy & $45(5.6)$ & $21(5.4)$ & $24(5.9)$ & \\
\hline Air Force ${ }^{\dagger}$ & $1(0.1)$ & $0(0)$ & $1(0.2)$ & \\
\hline Military Rank, n (\%) & & & & 0.04 \\
\hline Enlisted & 767 (95.9) & $369(94.4)$ & 398 (97.3) & \\
\hline Other/Unknown & 372 (46.5) & 217 (55.5) & 155 (37.9) & \\
\hline Blast Mechanism, $n$ (\%) & & & & 0.15 \\
\hline IED & $678(84.8)$ & 336 (85.9) & 342 (83.6) & \\
\hline Mortar & $32(4.0)$ & $10(2.6)$ & $22(5.4)$ & \\
\hline Grenade & $37(4.6)$ & $16(4.1)$ & $21(5.1)$ & \\
\hline Other & $53(6.6)$ & $29(7.4)$ & $24(5.9)$ & \\
\hline Head Injury, $n$ (\%) & & & & $<0.001$ \\
\hline No & 330 (41.3) & 195 (49.9) & $135(33.0)$ & \\
\hline Yes & $470(58.8)$ & $196(50.1)$ & $274(67.0)$ & \\
\hline
\end{tabular}

tinnitus and TM rupture. In univariate analysis, military personnel with hearing loss or tinnitus outcomes were significantly more likely to experience TM rupture at the point of injury. Inner/middle ear injury involving tinnitus, however, was not independently associated with either outcome. Those with hearing loss were significantly less likely to be serving in the Marine Corps or injured by other/unspecified blast mechanism, but were more likely to have concomitant head injury and higher ISSs overall than those without hearing loss. Military personnel with tinnitus outcomes were significantly less likely to be injured by other/unspecified blast mechanisms, more likely to have concomitant head injury, and more likely to have a higher ISS than those without tinnitus.

Multiple logistic regression was used to assess the combined effects of inner/middle ear injury involving tinnitus, TM rupture, and significant covariates on the occurrence of hearing loss and tinnitus outcomes. After adjusting for ear injury involving tinnitus, age, service branch, blast mechanism, head injury, and ISS, military personnel with TM rupture had greater than sixfold higher odds of hearing loss than those without TM rupture $(\mathrm{OR}=6.65,95 \% \mathrm{CI}=5.04-8.78)$. Inner $/$ middle ear injury involving tinnitus, however, was not associated 
Table 3.

Percentage and odds ratios (ORs) of inner/middle ear injury with tinnitus and tympanic membrane rupture by selected characteristics among U.S. servicemembers wounded in Operation Iraqi Freedom with hearing protection status information, 2004-2008.

\begin{tabular}{|c|c|c|c|c|c|c|c|}
\hline \multirow{3}{*}{ Variable } & \multirow{3}{*}{$\begin{array}{c}\text { Total } \\
(n=800)\end{array}$} & \multicolumn{3}{|c|}{ Inner/Middle Ear Injury Involving Tinnitus } & \multicolumn{3}{|c|}{ Tympanic Membrane Rupture } \\
\hline & & \multirow{2}{*}{$\%$} & \multicolumn{2}{|c|}{ OR (95\% CI) } & \multirow{2}{*}{$\%$} & \multicolumn{2}{|c|}{ OR (95\% CI) } \\
\hline & & & Unadjusted & Adjusted* & & Unadjusted & Adjusted $^{\dagger}$ \\
\hline Not Worn & 409 & 31.5 & 1.00 & 1.00 & 5.9 & 1.00 & 1.00 \\
\hline Worn & 391 & 15.9 & $0.41(0.29-0.58)$ & $0.57(0.39-0.82)$ & 6.6 & $1.14(0.64-2.03)$ & $0.86(0.46-1.62)$ \\
\hline \multicolumn{8}{|l|}{ Branch of Service } \\
\hline Army & 568 & 10.2 & 1.00 & 1.00 & 6.5 & 1.00 & - \\
\hline Marine Corps & 186 & 28.2 & $3.45(2.07-5.73)$ & $2.56(1.49-4.40)$ & 6.0 & $0.92(0.47-1.82)$ & - \\
\hline Navy & 45 & 26.7 & $3.20(1.42-7.21)$ & $2.38(1.00-5.66)$ & 8.7 & $1.42(0.43-4.61)$ & - \\
\hline Air Force & 1 & 0.0 & - & - & 0.0 & - & - \\
\hline \multicolumn{8}{|l|}{ Occupational Specialty } \\
\hline Infantry & 428 & 26.2 & 1.00 & - & 6.8 & 1.00 & - \\
\hline Other/Unspecified & 372 & 21.2 & $0.76(0.55-1.06)$ & - & 5.6 & $0.82(0.46-1.47)$ & - \\
\hline \multicolumn{8}{|l|}{ Blast Mechanism } \\
\hline IED & 678 & 24.9 & 1.00 & - & 6.2 & 1.00 & 1.00 \\
\hline Mortar & 32 & 15.6 & $0.56(0.21-1.47)$ & - & 6.3 & $1.01(0.23-4.37)$ & $0.60(0.13-2.83)$ \\
\hline Grenade & 37 & 13.5 & $0.47(0.18-1.23)$ & - & 16.2 & $2.93(1.16-7.42)$ & $2.94(1.02-8.46)$ \\
\hline Other & 53 & 22.6 & $0.88(0.45-1.72)$ & - & 0.0 & - & - \\
\hline \multicolumn{8}{|l|}{ Head Injury } \\
\hline
\end{tabular}

with hearing loss outcome after adjusting for covariates (OR $=1.11,95 \%$ CI 0.82-1.51). By contrast, both inner/ middle ear injury involving tinnitus and TM rupture were associated with tinnitus outcomes in multiple logistic regression analysis; after adjusting for covariates, military personnel with inner/middle ear injury involving tinnitus $(\mathrm{OR}=1.56,95 \% \mathrm{CI}=1.10-2.20)$ and $\mathrm{TM}$ rupture (OR $=4.34,95 \% \mathrm{CI}=3.12-6.04)$ were more likely to be diagnosed with tinnitus within 1 yr after injury than those with other injuries.

\section{DISCUSSION}

Our findings confirm that ear injury is common among servicemembers injured in a blast during combat deployment. In the present study, nearly one third of all personnel sustained blast-related ear injury. This finding is within range of civilian literature on terrorist bombings, which demonstrates ear injury prevalence from 24 to 40 percent [27-30]. Overall prevalence of blast-related ear injuries reported in recent military studies, however, is 
JRRD, Volume 50, Number 6, 2013

Table 4.

Percentage and odds ratios (ORs) of hearing loss and tinnitus outcomes for specific blast-related ear injuries among U.S. servicemembers wounded in Operation Iraqi Freedom, 2004-2008.

\begin{tabular}{|c|c|c|c|c|c|c|c|}
\hline \multirow{3}{*}{ Variable } & \multirow{3}{*}{$\begin{array}{c}\text { Total } \\
(n=3,824)\end{array}$} & \multicolumn{3}{|c|}{ Hearing Loss } & \multicolumn{3}{|c|}{ Tinnitus } \\
\hline & & \multirow{2}{*}{$\%$} & \multicolumn{2}{|c|}{ OR (95\% CI) } & \multirow{2}{*}{$\%$} & \multicolumn{2}{|c|}{ OR (95\% CI) } \\
\hline & & & Unadjusted & Adjusted* & & Unadjusted & Adjusted $^{\dagger}$ \\
\hline No & 3,091 & 12.1 & 1.00 & 1.00 & 5.8 & 1.00 & 1.00 \\
\hline No & 3,519 & 8.9 & 1.00 & 1.00 & 4.8 & 1.00 & 1.00 \\
\hline Yes & 305 & 42.6 & 7.58 (5.88-9.78) & $6.65(5.04-8.78)$ & 20.9 & $5.26(3.84-7.22)$ & $4.34(3.12-6.04)$ \\
\hline Age, yr & - & - & $1.02(1.00-1.04)$ & $1.02(1.00-1.04)$ & & $1.01(0.99-1.04)$ & $1.02(1.00-1.05)$ \\
\hline \multicolumn{8}{|l|}{ Branch of Service } \\
\hline Army & 767 & 15.5 & 1.00 & 1.00 & 6.5 & 1.00 & - \\
\hline \multicolumn{8}{|l|}{ Military Rank } \\
\hline Enlisted & 3,655 & 11.6 & 1.00 & - & 6.0 & 1.00 & - \\
\hline Officer/Warrant Officer & 169 & 11.8 & $1.02(0.63-1.65)$ & - & 8.9 & $1.53(0.89-2.66)$ & - \\
\hline \multicolumn{8}{|l|}{ Occupational Specialty } \\
\hline Infantry & 1,991 & 10.9 & 1.00 & - & 6.2 & 1.00 & - \\
\hline Other/Unspecified & 1,833 & 12.4 & $1.16(0.95-1.41)$ & - & 6.0 & $0.97(0.74-1.26)$ & - \\
\hline \multicolumn{8}{|l|}{ Blast Mechanism } \\
\hline IED & 2,748 & 12.4 & 1.00 & 1.00 & 6.7 & 1.00 & 1.00 \\
\hline Mortar & 325 & 8.6 & $0.69(0.45-1.00)$ & $0.79(0.52-1.22)$ & 4.3 & $0.62(0.36-1.09)$ & $0.75(0.42-1.32)$ \\
\hline Serious/Severe & 571 & 32.9 & $5.75(4.62-7.13)$ & $5.12(4.04-6.49)$ & 13.1 & $2.96(2.22-3.96)$ & 2.59 (1.89-3.55) \\
\hline
\end{tabular}

limited and mixed. Although Gondusky and Reiter found that ear injuries were the most common injury sustained by a mechanized battalion of Marines from Operation Iraqi Freedom, the analysis did not report the prevalence of ear injuries among all Marines in the sample and included nonblast injuries [11]. A study of battle injuries among British personnel from Iraq and Afghanistan found that ear-injury prevalence was only 5 percent [31]. The large discrepancy in prevalence between this study and our study may reflect differences in data sources used. Data for the British study by Breeze et al. were obtained from the Joint Theater Trauma Registry, which initiates data collection at a higher level of care than the EMED, and thus, may not capture as many records of personnel 
with minor injuries who are immediately returned to duty from far-forward treatment facilities in theater [31].

An additional explanation for the difference between our findings and those of Breeze et al. may be differences in diagnostic inclusion criteria. Breeze et al. identified only TM rupture, ossicular injury, and external ear injury for analysis. Although external ear injury was not within the scope of our study, we included all inner and middle ear injury codes in the AIS scoring system. While the occurrence of TM rupture in our study is within range of previous military reports [11-12,31-32], the most common ear injury diagnosis in the present study (inner/middle ear injury involving tinnitus) is new to the AIS scoring system as of 2005, and it has not been previously described in studies on blast-related ear injury. It is important to note that inner/middle ear injury involving tinnitus could be diagnosed based only on the presence of tinnitus following blast exposure. Given that tinnitus can occur from other causes, such as head injury or as a side effect of ototoxic medications [33-34], and that it can occur in conjunction with other ear injuries that may be difficult to diagnose in theater, some individuals may have been misclassified. Nevertheless, symptoms of tinnitus are one of the most commonly reported auditory complaints following blast exposure in both military and civilian populations [17,27,29], and because tinnitus may adversely affect hearing acuity and operational readiness [21], servicemembers presenting with tinnitus in theater should be periodically monitored for symptom persistence and improvement with audiometric measurements and clinical tinnitus assessments such as the Tinnitus Handicap Inventory [35] and the Tinnitus Handicap Questionnaire [36].

One of the primary findings of the present study was that hearing protection reduced the odds of inner/middle ear injury involving tinnitus, but was not statistically associated with TM rupture. These findings are not altogether surprising when considering that rupture of the TM requires greater pressure differentials than damage to the inner ear [27]. In addition, the factors that influence the type and degree of auditory damage, such as the duration and peak pressure of the blast wave as well as the orientation of the ear [5,14-15], might also influence the effectiveness of hearing protection. Although modern hearing protection devices appear to mitigate ear injuries involving tinnitus, they may be ill-equipped to attenuate injuries resulting from more extreme pressure differentials experienced on the battlefield, such as TM rupture. Nevertheless, hearing protection is warranted for all ser- vicemembers at risk of blast exposure during combat deployment.

It is important to note, however, that our hearing protection results are in contrast with a recent report by Xydakis et al., who found that hearing protection significantly reduced the risk of TM rupture among blast injury patients treated at an Air Force theater hospital in Iraq [37]. One possible explanation for the difference in findings is that there may have been too few cases of TM rupture in the hearing protection subanalysis to detect a statistical association. In addition, the types of hearing protection used may have affected the results, and this information was not available for the present analysis. Hearing protection devices cited in the Xydakis et al. study included earplugs and electronically aided earmuffs, but the independent effect of each device was not examined. One report by Jönsson demonstrated that earplugs confer more protection from blast waves than ear muffs [38], which suggests that earplugs could have been more widely used in the Xydakis et al. study than in our sample. Future studies are needed to compare the effects of the modern hearing protection devices in preventing blast-related ear injuries.

Multiple studies have demonstrated the detrimental effects of blasts on hearing outcomes in both military and civilian populations $[12,17,28-30]$. In the present study, more than 1 in 10 servicemembers were diagnosed with hearing-related morbidity within 1 yr after a blast injury. Although ear injuries involving tinnitus at the point of injury were more common, TM rupture was the strongest predictor of hearing loss and tinnitus outcomes diagnosed within 1 yr after injury. This finding is consistent with a previous military study that demonstrated hearing impairment in servicemembers is common following blastrelated TM rupture [12], and it is expected given that the greater blast forces required to rupture the TM would also be likely to disrupt the key inner ear structures that transmit and amplify sound vibrations [27]. As such, personnel with TM rupture in theater should be periodically monitored for the development of hearing loss and tinnitus symptoms that could affect fitness for duty.

As mentioned previously, the findings of this study are limited by missing information in the hearing protection subanalysis, including information pertaining to the type and proper use of hearing protection. Early iterations of the EMED data collection form did not include an option to report hearing protection usage, and this may account for the large proportion of missing data. In addition, at the time 
of this study, only data for patients treated at Navy-Marine Corps treatment facilities in theater were available in the EMED for analysis and were composed primarily of Marine Corps personnel. As such, the results of this study may not generalize and service-specific findings should be interpreted with caution. Further, the use of diagnoses for hearing and tinnitus outcomes from military medical databases may have led to an underestimate of hearing-related morbidity. It is possible that only the most severe cases of hearing loss and tinnitus presented for care within the 12 mo follow-up period after blast injury. In addition, the use of AIS codes to identify blast-related ear injuries has not been previously described and may account for misclassification of some injuries that are diagnosed based only on clinical examination, particularly among servicemembers who are immediately returned to duty from forwarddeployed treatment facilities where diagnostic techniques such as audiometry, binocular microscopy, and temporal bone CT scan are not readily available. Future prospective studies using these additional measures are needed.

Despite these limitations, the use of the "inner/middle ear injury involving tinnitus" diagnosis was a unique strength of this study and may indicate damage to the auditory system that is not detectable by other means. Further, because of the high prevalence of tinnitus injury and risk of progressive deterioration in hearing with continuous noise exposure [39], this diagnosis should be considered when targeting individuals for clinical interventions. Future studies utilizing clinical and audiometric data are needed and should distinguish between inner and middle ear tinnitus as well as attempt to quantify the significance of this diagnosis through an analysis of treatment outcomes. The exclusion of servicemembers with history of hearing loss and/or tinnitus before injury was a strength of this study, which allowed for the prospective analysis of new-onset hearing loss and tinnitus outcomes, while controlling for the effect of prior diagnoses on subsequent hearing-related morbidity. Lastly, the use of the EMED allowed for analysis of diagnostic and hearing protection information closest to the point of injury, and for correlation of these battlefield data with hearingrelated outcomes within 1 yr after injury.

\section{CONCLUSIONS}

Ear injuries and hearing impairment are frequent consequences of blast exposure during combat deployment.
Hearing protection is warranted for all servicemembers at risk of blast exposure and may mitigate ear injury involving tinnitus. TM rupture is strongly associated with hearing loss and tinnitus diagnosed within $1 \mathrm{yr}$ after injury. Blast-related ear injuries should be closely monitored in theater and throughout the continuum of care to identify hearing-related morbidity that can affect servicemembers' operational readiness. Otoscopic and hearing examinations should be mandated for all blast-injured military personnel to diagnose and treat servicemembers with ear injury. Personnel can be trained on the importance of preventive measures for hearing loss by reviewing the advantages and disadvantages of the current in-the-ear and overthe-ear systems. If tinnitus occurs, therapy for mitigation of the sensation can include sound generation technologies and counseling techniques to minimize stress and reinjury.

\section{ACKNOWLEDGMENTS}

\section{Author Contributions:}

Study concept and design: A. L. Dougherty, A. J. MacGregor, P. P. Han, E. Viirre, K. J. Heltemes, M. R. Galarneau.

Data acquisition: A. L. Dougherty, P. P. Han, K. J. Heltemes, M. R. Galarneau.

Data analysis: A. L. Dougherty.

Data interpretation: A. L. Dougherty, A. J. MacGregor, E. Viirre.

Drafting of manuscript: A. L. Dougherty.

Critical revision of manuscript for important intellectual content: A. J. MacGregor, P. P. Han, K. J. Heltemes, E. Viirre, M. R. Galarneau.

Financial Disclosures: Dr. Erik Viirre has a financial interest in Tinnitus Otosound Products LLC.

Funding/Support: This material was based on work supported by the U.S. Navy Bureau of Medicine and Surgery (work unit number 60808). Additional Contributions: The authors thank Science Applications International Corporation for its contribution to this work.

Institutional Review: This research has been conducted in compliance with all applicable Federal regulations governing the protection of human subjects in research (protocol NHRC.2003.0025).

Disclaimer: The views and opinions expressed herein are those of the authors and do not necessarily reflect the official policy or position of the Department of the Navy, Department of Defense, or the U.S. Government. Approved for public release; distribution is unlimited.

\section{REFERENCES}

1. Reister FA. Medical statistics in World War II. Washington (DC): Department of the Army, Office of the Surgeon General; 1975. 
2. Reister FA. Battle casualties and medical statistics: US Army experience in the Korean War. Washington (DC): Department of the Army, Office of the Surgeon General; 1973.

3. Champion HR, Bellamy RF, Roberts CP, Leppaniemi A. A profile of combat injury. J Trauma. 2003;54(5 Suppl):S13-19. [PMID:12768096]

4. Institute of Medicine. Gulf war and health, volume 7: Long-term consequences of traumatic brain injury. Washington (DC): The National Academies Press; 2009.

5. Darley DS, Kellman RM. Otologic considerations of blast injury. Disaster Med Public Health Prep. 2010;4(2):145-52. [PMID:20526137]

http://dx.doi.org/10.1001/dmphp.D-08-00057R2

6. Centers for Disease Control and Prevention. Blast injuries: Ear blast injuries [Internet]. Atlanta (GA): Centers for Disease Control and Prevention; 2008 [updated 2008 May 12; cited 2010 Jun 28]. Available from: http://www.bt.cdc.gov/ masscasualties/blastinjury-ear.asp

7. Mayorga MA. The pathology of primary blast overpressure injury. Toxicology. 1997;121(1):17-28. [PMID:9217312] http://dx.doi.org/10.1016/S0300-483X(97)03652-4

8. Killion MC, Monroe T, Drambarean V. Better protection from blasts without sacrificing situational awareness. Int J Audiol. 2011;50(1 Suppl 1):S38-45. [PMID:21288067] http://dx.doi.org/10.3109/14992027.2010.540581

9. Tilghman A. High-tech ear gear offers more protection [Internet]. Springfield (VA): Marine Corps Times; 2008 [cited 2011 Mar 9]. Available from: http://www.marinecorpstimes.com/ news/2008/03/marine hearing 030108/

10. Meltzer P. Research lab helps warfighters with communications and hearing protector systems [Internet]. WrightPatterson Air Force Base (OH): Air Force Print News; 2007 Feb 2 [cited 2011 Mar 9]. Available from: http:// www.afmc.af.mil/news/story print.asp?id=123042791

11. Gondusky JS, Reiter MP. Protecting military convoys in Iraq: An examination of battle injuries sustained by a mechanized battalion during Operation Iraqi Freedom II. Mil Med. 2005;170(6):546-49. [PMID:16001610]

12. Ritenour AE, Wickley A, Ritenour JS, Kriete BR, Blackbourne LH, Holcomb JB, Wade CE. Tympanic membrane perforation and hearing loss from blast overpressure in Operation Enduring Freedom and Operation Iraqi Freedom wounded. J Trauma. 2008;64(2 Suppl):S174-78, discussion S178. [PMID:18376162] http://dx.doi.org/10.1097/TA.0b013e318160773e

13. DePalma RG, Burris DG, Champion HR, Hodgson MJ. Blast injuries. N Engl J Med. 2005;352(13):1335-42.

[PMID:15800229] http://dx.doi.org/10.1056/NEJMra042083

14. Garth RJ. Blast injury of the auditory system: A review of the mechanisms and pathology. J Laryngol Otol. 1994;
108(11):925-29. [PMID:7829942]

http://dx.doi.org/10.1017/S0022215100128555

15. Kerr AG, Byrne JE. Surgery of violence. IV. Blast injuries of the ear. BMJ. 1975;1(5957):559-61. [PMID:1139149]

http://dx.doi.org/10.1136/bmj.1.5957.559

16. Kerr AG. Blast injury to the ear: A review. Rev Environ Health. 1987;7(1-2):65-79. [PMID:3330834] http://dx.doi.org/10.1515/REVEH.1987.7.1-2.65

17. Cave KM, Cornish EM, Chandler DW. Blast injury of the ear: Clinical update from the global war on terror. Mil Med. 2007;172(7):726-30. [PMID:17691685]

18. Veterans Benefits Administration annual benefits report fiscal year 2010 [Internet]. Washington (DC): U.S. Department of Veterans Affairs; 2010. Available from: http:// www.vba.va.gov/REPORTS/abr/index.asp

19. Chandler DW. Blast-related ear injury in current U.S. military operations: Role of audiology on the interdisciplinary team: role of audiology on the interdisciplinary team [Internet]. Rockville (MD): The AHSA Leader; 2006 [cited 2011 Mar 9]. Available from: http://www.asha.org/Publications/ leader/2006/060711/f060711a2.htm

20. Fausti SA, Wilmington DJ, Helt PV, Helt WJ, Konrad-Martin D. Hearing health and care: The need for improved hearing loss prevention and hearing conservation practices. J Rehabil Res Dev. 2005;42(4 Suppl 2):45-62. [PMID:16470464] http://dx.doi.org/10.1682/JRRD.2005.02.0039

21. McIlwain DS. The Army Hearing Program: Expanding audiology's military reach [Internet]. Rockville (MD): The ASHA Leader; 2009 [cited 2011 Mar 9]. Available from: http://www.asha.org/Publications/leader/2009/090120/ 090120g.htm

22. Phillips YY, Zajtchuk JT. Blast injuries of the ear in military operations. Ann Otol Rhinol Laryngol Suppl. 1989; 140:3-4. [PMID:2497696]

23. Galarneau MR, Hancock WC, Konoske P, Melcer T, Vickers RR, Walker GJ, Zouris JM. The Navy-Marine Corps Combat Trauma Registry. Mil Med. 2006;171(8):691-97. [PMID:16933807]

24. Hart AC, Stegman MS, Ford B, editors. ICD-9-CM professional for physicians, volumes 1 \& 2: International Classification of Diseases, 9th Revision, Clinical Modification. 6th ed. Salt Lake City (UT): Igenix; 2008.

25. Gennarelli T, Wodzon E. The Abbreviated Injury Scale2005. Des Plaines (IL): Association for the Advancement of Automotive Medicine; 2005.

26. Baker SP, O’Neill B, Haddon W Jr, Long WB. The injury severity score: A method for describing patients with multiple injuries and evaluating emergency care. J Trauma. 1974;14(3):187-96. [PMID:4814394] http://dx.doi.org/10.1097/00005373-197403000-00001

27. Mrena R, Pääkkönen R, Bäck L, Pirvola U, Ylikoski J. Otologic consequences of blast exposure: A Finnish case study 
of a shopping mall bomb explosion. Acta Otolaryngol. 2004;124(8):946-52. [PMID:15513532]

http://dx.doi.org/10.1080/00016480310017045

28. Tungsinmunkong S, Chongkolwatana C, Piyawongvisal W, Atipas S, Namchareonchaisuk S. Blast injury of the ears: The experience from Yala Hospital, Southern Thailand. J Med Assoc Thai. 2007;90(12):2662-68. [PMID:18386718]

29. Persaud R, Hajioff D, Wareing M, Chevretton E. Otological trauma resulting from the Soho Nail Bomb in London, April 1999. Clin Otolaryngol Allied Sci. 2003;28(3):203-6. [PMID:12755756] http://dx.doi.org/10.1046/j.1365-2273.2003.00688.x

30. Walsh RM, Pracy JP, Huggon AM, Gleeson MJ. Bomb blast injuries to the ear: The London Bridge incident series. J Accid Emerg Med. 1995;12(3):194-98. [PMID:8581246] http://dx.doi.org/10.1136/emj.12.3.194

31. Breeze J, Cooper H, Pearson CR, Henney S, Reid A. Ear injuries sustained by British service personnel subjected to blast trauma. J Laryngol Otol. 2011;125(1):13-17. [PMID:20950512] http://dx.doi.org/10.1017/S0022215110002215

32. Harrison CD, Bebarta VS, Grant GA. Tympanic membrane perforation after combat blast exposure in Iraq: A poor biomarker of primary blast injury. J Trauma. 2009;67(1):210-11. [PMID:19590337] http://dx.doi.org/10.1097/TA.0b013e3181a5f1db

33. Myers PJ, Henry JA, Zaugg TL, Kendall CJ. Tinnitus evaluation and management considerations for persons with mild traumatic brain injury [Internet]. Rockville (MD): American Speech-Language-Hearing Association; 2011 [cited 2011 Jun 9]. Available from: http://www.asha.org/ aud/articles/TinnitusTBI.htm

34. Fausti SA, Wilmington DJ, Gallun FJ, Myers PJ, Henry JA. Auditory and vestibular dysfunction associated with blastrelated traumatic brain injury. J Rehabil Res Dev. 2009;
46(6):797-810. [PMID:20104403]

http://dx.doi.org/10.1682/JRRD.2008.09.0118

35. Newman CW, Jacobson GP, Spitzer JB. Development of the Tinnitus Handicap Inventory. Arch Otolaryngol Head Neck Surg. 1996;122(2):143-48. [PMID:8630207] http://dx.doi.org/10.1001/archotol.1996.01890140029007

36. Kuk FK, Tyler RS, Russell D, Jordan H. The psychometric properties of a tinnitus handicap questionnaire. Ear Hear. 1990;11(6):434-45. [PMID:2073977] http://dx.doi.org/10.1097/00003446-199012000-00005

37. Xydakis MS, Bebarta VS, Harrison CD, Conner JC, Grant GA, Robbins AS. Tympanic-membrane perforation as a marker of concussive brain injury in Iraq. N Engl J Med. 2007;357(8):830-31. [PMID:17715421] http://dx.doi.org/10.1056/NEJMc076071

38. Jönsson A. Pressure measurements in the external auditory canal of a human head model exposed to air shock waves (FOA Report C 20802-2.3). Stockholm (Sweden): National Defence Research Establishment; 1990.

39. Segal S, Harell M, Shahar A, Englender M. Acute acoustic trauma: Dynamics of hearing loss following cessation of exposure. Am J Otol. 1988;9(4):293-98. [PMID:3177612]

Submitted for publication February 2, 2012. Accepted in revised form January 23, 2013.

This article and any supplementary material should be cited as follows:

Dougherty AL, MacGregor AJ, Han PP, Viirre E, Heltemes KJ, Galarneau MR. Blast-related ear injuries among U.S. military personnel. J Rehabil Res Dev. 2013; 50(6):893-904.

http://dx.doi.org/10.1682/JRRD.2012.02.0024

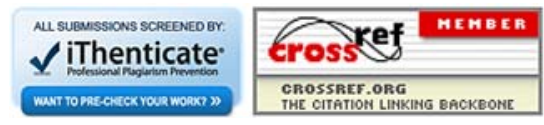

